\title{
RANCANG BANGUN ALAT UJI KABEL EKG
}

\author{
Mulyatno \\ Program studi DIV- Elektromedik Universitas MH Thamrin
}

\begin{abstract}
ABSTRAK
Saat ini Pesawat Elektro Kardiograf hampir sudah menjadi kebutuhan utama untuk diagnostik penyakit jantung. Kesiapan alat harus terus terjaga (siap digunakan), karena itu wajib dilakukan pemeliharaan ElektroKardiograf oleh para elektromedis (teknisi elektromedik). Beberapa kerusakan yang sering dijumpai adalah masalah kabel elektroda, biasanya kabel ini terdiri dari 10 elektroda, untuk menguji baik tidaknya kabel ini umumnya menggunakan Multitester/AVO meter pada posisi ohm. Kelemah pengujian menggunakan AVO meter adalah harus menguji satu persatu kabel dengan beberapa posisi, Metode : Untuk menghasilkan alat ini menggunakan System Developmen Life Cycle (SDLC) yang terdiri dari tahapan perencanaan,analisis, desain,konstruksi dan implementasi ${ }^{(1)}$. Selain itu peneliti membuat 2 rancangan alat dan membandingkan keduanya, desain alat pertama menggunakan running led, sedang yang kedua LED hidup jika kabel bagus dan Mati jika kabel putus. Tujuannya yaitu Menghasilkan alat untuk menguji kabel EKG secara simultan 10 kabel lead elektroda. Hasilnya yaitu_Kedua Alat berfungsi dengan baik dan perbandingan 2 rancangan tersebut, ternyata lebih efektif tanpa menggunakan Running LED.
\end{abstract}

\section{PENDAHULUAN}

Elektro Kardiograf/EKG/ECG ini adalah alat untuk mengukur aktivitas listrik yang dihasilkan oleh jantung ${ }^{(2)}$. ECG saat ini sudah menjadi alat yang umum digunakan pada klinik, puskesmas dan rumah sakitrumah sakit. Kesiapan alat harus terus terjaga (siap digunakan), karena itu wajib dilakukan pemeliharaan Alat Elekto Kardiograf oleh para elektromedis (teknisi elektromedik). Permasalahan yang sering timbul pada alat EKG adalah kabel elektroda sering putus atau koneksinya tidak bagus, hal ini wajar karena sering digunakan ke pasien sering ketekuk/ terpilir atau tertarik. Elektroda kabel EKG biasa terdiri dari 10 kabel pada EKG standard, kecuali pada pasien monitor atau alat treadmill. Saat ini kebanyakan teknisi untuk menguji 10 kabel tersebut harus satu persatu menggunakan Multi tester / AVO meter. Hal itu tentu merepotkan teknisi dan cukup memakan waktu, dengan kata lain tidak efektif dan efisien. Tujuan nya untuk Menghasilkan alat sederhana menguji kabel EKG yang mampu menguji kabel EKG secara simultan seluruh kabel lead elektroda. Manfaatnya Meringankan beban teknisi dalam pengujian kabel elektroda EKG. Rumusan Masalah Bagaimana merancang dan membangun alat uji kabel elektroda EKG secara simultan seluruh kabel lead.?

\section{Tinjauan Pustaka}

\section{A. Alat Elektro Kardiograf /EKG}

EKG adalah salah satu alat medis yang merekam aktifitas listrik pada jantung. Alat EKG biasanya memiliki 10 kabel elektroda yang digunakan untuk standard pengukuruan. Standard pengukuran tersebut dari beberapa posisi sebagai berikut :

1. Sandapan Standar Bipolar (Lead Ekstremitas Bipolar) terdiri atas 3 lead $^{(3)}$ :

$\sim$ Lead I : RA (-) dan LA (+) ==> Vektor Frontal Plane +0 derajat

$\sim$ Lead II : RA (-) dan LL (+) ==> Vektor Frontal Plane +60 derajat

$\sim$ Lead III : LA (-) dan LL (+) ==> Vektor Fronta Plane +120 derajat 
2. Unipolar Augmented Extremity (frontal plane) $)^{(3)}$ :

$\sim$ Lead aVR : ==> Vektor Frontal Plane -150 derajat

$\sim$ Lead aVL : ==> Vektor Frontal Plane - 30 derajat

～Lead aVF : ==> Vektor Frontal Plane +90 derajat

3. Lead Prekordial melihat arus listrik dari bidang horizontal dan terdiri atas 6 lead $^{(3)}$ :

Lead V1 : Terletak pada ICS 4 Linea parasternalis kanan

$\sim$ Lead V2: Terletak pada ICS 4 Linea parasternalis kiri

$\sim$ Lead V3 : Terletak diantara pertengahan Lead V2 dan V4

$\sim$ Lead V4 : Terletak pada ICS 5 Linea Midklavikularis kiri

Lead V5 : Terletak sejajar lead V4 di Linea Axillaris Anterior Kiri

Lead V6 : Terletak sejajar lead V4 di Linea MidAxillaris Kiri

B. LED

LED (Light Emitting Dioda) adalah dioda yang dapat memancarkan cahaya pada saat mendapat arus bias maju (forward bias). LED (Light Emitting Dioda) dapat memancarkan cahaya karena menggunakan dopping galium, arsenic dan phosporus. Jenis doping yang berbeda diata dapat menhasilkan cahaya dengan warna yang berbeda.

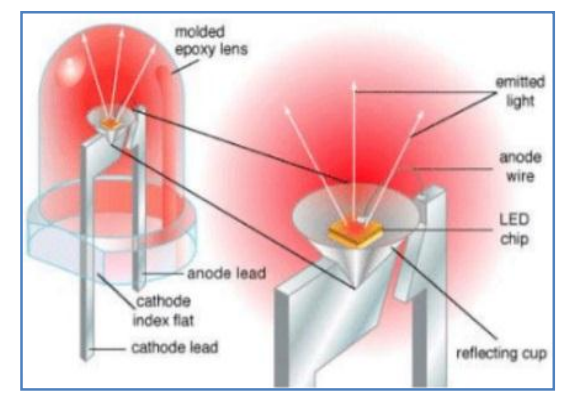

Gambar 1. Struktur LED ${ }^{(5)}$

Kebanyakan LED mengalirkan arus cukup rendah yaitu maksimal $25 \mathrm{~mA}$ dengan tegangan Jatuh sekitar 1,7 Volt, lebih dari itu umumnya membuat LED rusak. Perbedaan warna LED juga mempengaruhi tegangan jatuh pada LED.

\begin{tabular}{|l|l|r|r|}
\hline Color & Material & Wavelength $(\mathrm{nm})$ & V-forward \\
\hline Super Red & GaAlAs & 660 & 1.8 \\
\hline Green & GaP & 565 & 2 \\
\hline Red & GaAsP & 635 & 2 \\
\hline Red & AlInGaP & 636 & 2 \\
\hline Orange & AlInGaP & 610 & 2.1 \\
\hline Yellow & AlinGaP & 590 & 2.1 \\
\hline Amber & GaAsP & 705 & 2.1 \\
\hline Red & GaP & 555 & 2.2 \\
\hline Green & GaP & 574 & 3.5 \\
\hline Green & AlInGaP & 430 & 3.5 \\
\hline Blue & SiC & 505 & 3.5 \\
\hline Green & InGaN & 470 & 3.5 \\
\hline Blue & InGaN & & 3.7 \\
\hline White & InGaN & 525 & 4.5 \\
\hline Green & InGaN & 525 & 430 \\
\hline Green & InGaN & & 25 \\
\hline Blue & SiC & & \\
\hline
\end{tabular}

Tabel 1. Jenis warna LED $^{(5)}$ 
C. Transistor sebagai Saklar

Transistor adalah sebagai saklar bila berada pada dua daerah kerjanya yaitu daerah jenuh (saturasi) dan daerah mati (cut-off).

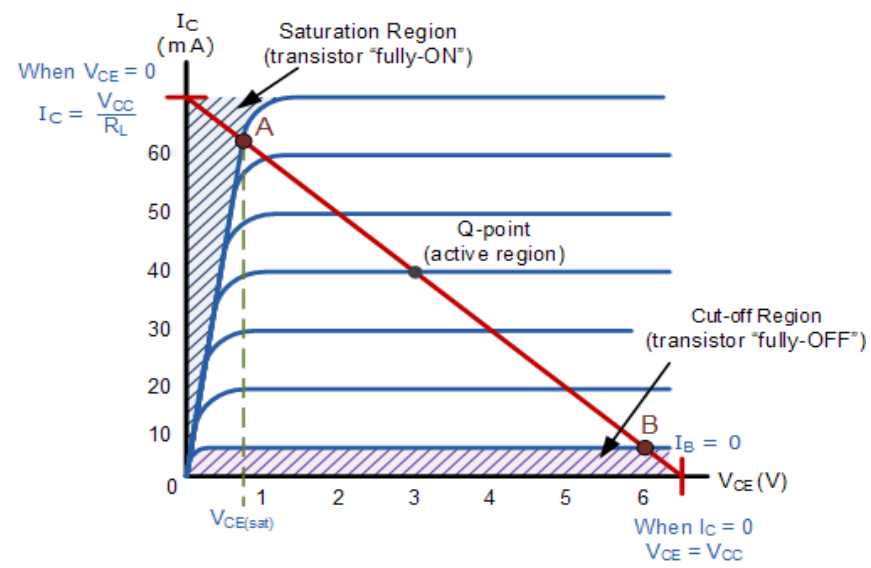

Gambar 2. Karakteristik transistor ${ }^{(7)}$

D. IC 555

Rangkaian blok internal IC 555 terdiri dari pembagi tegangan menggunakan resistor, 2 unit komparator, RS flip-flop, penguat tegangan, dan transitor discharge. Dengan blok tersebut, IC 555 dapat dibangun beberapa rangkaian timer Astable Multivibrator, Monostable Multivibrator dan Bistable Multivibrator. Berikut rangkaian blok internal IC 555.

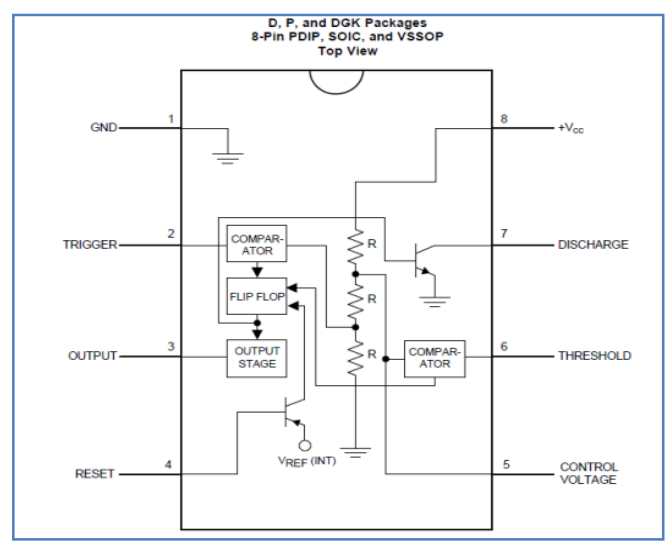

Gambar 2. Blok Skema Internal IC 555 ${ }^{(6)}$ 
Rangkaian Pembangkit clock atau astable multivibrator, seperti berikut ini :

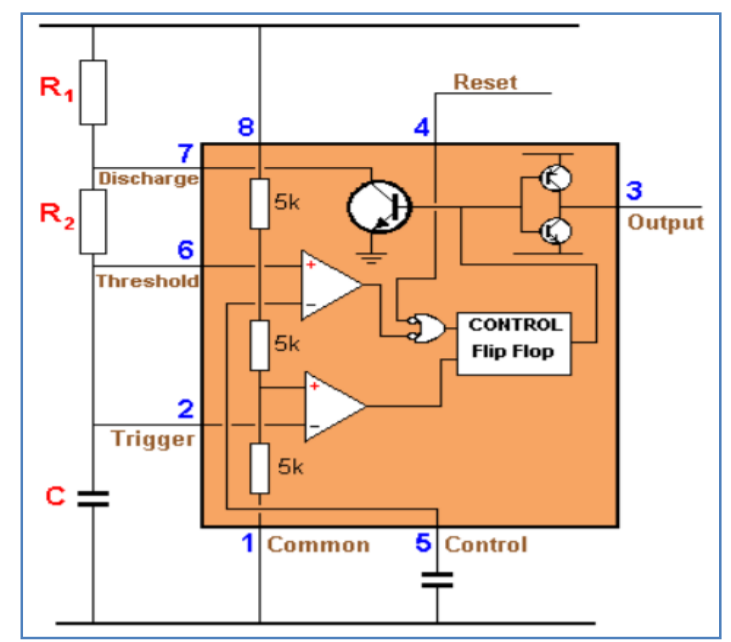

Gambar 4.Rangkaian dasar Astable Multivibrator ${ }^{(4)}$.

E. IC 4017

IC 4017 adalah IC ini adalah jenis IC Pencacah Decade (Decade Counter) dengan 10 output. IC ini menghasilkan 10 Output yaitu dari Q0 - Q9, setiap pencacahan hanya satu keluaran yang berlogika 1, ke sembilan keluaran lainnya berlogika 0 , jadi setiap saat hanya ada satu keluaran yang dapat berlogika 1 . IC interbuat dari CMOS (Complentary Metal Oxide Semiconductor), IC ini dapat bekerja pada tegangan DC 3Volt sampai dengan 15 Volt.

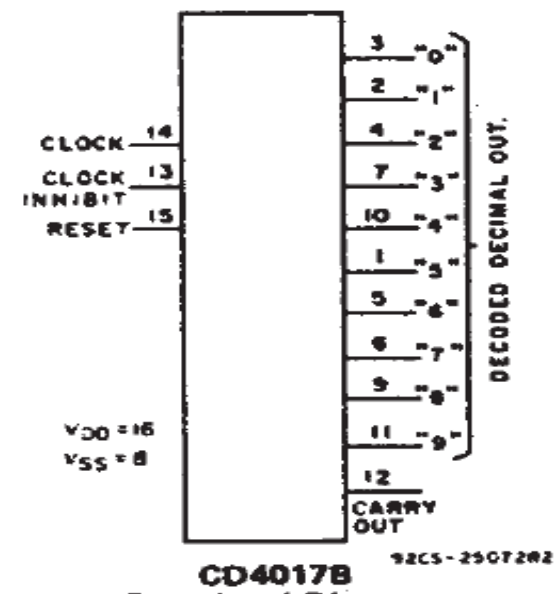

Functional Dingem

Gambar 5. Pin-pin pada IC $4017^{(8)}$

Bersama IC 555 yang berfungsi sebagai Clock, untuk menjadi rangkaian running LED, sebagai berikut:

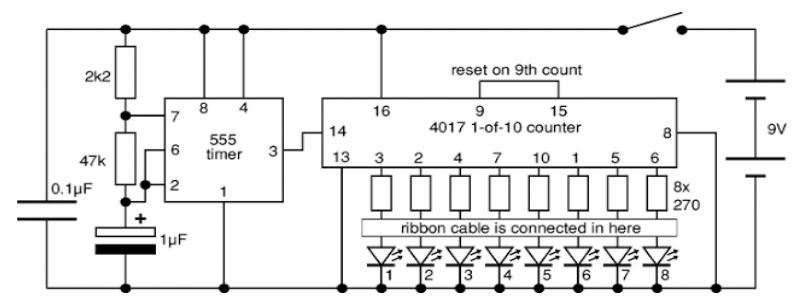

Gambar 6. Rangkaian Running LED ${ }^{(9)}$ 


\section{METODE}

Penelitian ini merupakan jenis penelitian dan pengembangan yang menggunakan System Life Developmen Life Cycle yang terdiri dari tahapan perencanaan (planning), analisis (analysis), desain (design), implementasi (implementation), uji coba ${ }^{(1)}$.

Adapun langkah-langkahnya adalah sebagai berikut:

1. Merumuskan masalah tentang pengukuran kabel lead EKG.

2. Mengumpulkan informasi tentang komponen-komponen yang akan digunakan.

3. Mendesain produk awal dengan membuat diagram blok sistem dan cara kerjanya.

4. Membangun/ kontruksi alat.

5. Melakukan uji coba alat.

6. Memperbaiki desain setelah melakukan validasi.

7. Melakukan uji coba Alat.

A. Desain Rangkaian Pertama

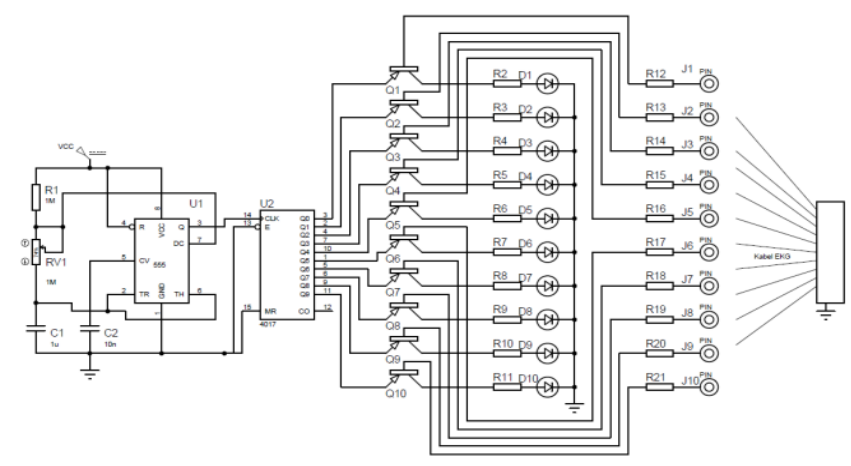

Gambar. 7 Desain Rangkaian Pertama

Desain rangkaian pertama, clock dibentuk dari rangkaian Astable Multivibrator IC555, menghasilkan frekuensi yang mampu diamati oleh mata, pada desain ini sekitar $0,5 \mathrm{~Hz}$ hingga $1,5 \mathrm{~Hz}$. Clock tersebut kemudian diumpan ke counter divider untuk menghasilkan Running LED. Jika salah satu LED atau lebih tidak menyala berarti ada kabel ECG yang putus. Karena ada beberapa kabel ECG memiliki resistor/tahanan sampai beberapa puluh kilo ohm, maka digunakan driver transistor sebagai saklar.

B. Ingrris

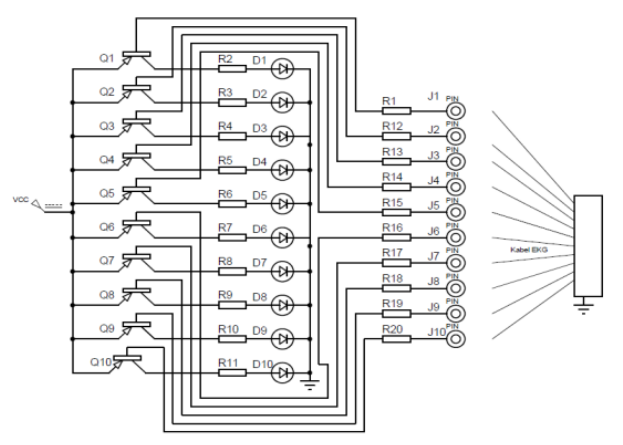

Gambar. 8 Desain Rangkaian kedua 
Pada Desain ke 2 sama seperti pada rangkaian 1, diperlukan driver transistor, kemudian dihubungkan dengan resistor pembatas arus dan LED indikatornya, sehingga led akan menyala terus (tidak bergantian/running LED) jika kabelnya bagus. Sebaliknya jika ada satu atau lebih LED yang padam, berarti terdapat kabel ECG yang putus (kabel pada led yang padam tersebut).

\section{Konstruksi dan Uji Coba}

Setelah rangkaian dibangun kemudian diuji coba, berkeja dengan baik sesuai rencana. Perbandingan implementasi dari kedua rangkain tersebut ternyata, rangkaian pertama relative membutuhkan konsentrasi untuk mengamati running led dibanding dengan rangkaian kedua yang langsung menyala saat kabel bagus dan padam saat kabel putus. Dengan kata lain, rangkaian kedua lebih efektif untuk di implementasi, karena memudahkan pengamatan teknisi.

\section{DAFTAR PUSTAKA}

1. SDLC, https://id.wikipedia.org/wiki/SDLC,

2. 7 Fungsi EKG Jantung, Jenis, Prosedur dan Biayanya, https://drjantung.com/fungsi-ekg-jantung.

3. Lead EKG - 12 Standar Lead, http://www.ina-ecg.com/2015/07/lead-ekg-12-standar-lead.html

4. Colin Mitchell, 50555 Circuit A free ebook, TALKING ELECTRONICS

5. Colin Mitchell, 30 LED Projects A free ebook, TALKING ELECTRONICS

6. LM555,Texas Instruments, SNAS548D -FEBRUARY 2000-REVISED JANUARY 2015

7. Transistor as a Switch, https://www.electronics-tutorials.ws/transistor/tran_4.html

8. CD4017B,CD4022B Types,Texas Instruments,Data sheet acquired from Harris Semiconductor SCHS027C - Revised February 2004

9. CD4017, http://elektronewbie.blogspot.com/2016/10/cd4017.html 